\title{
At the Hawk's Well and The Cat and the Moon
}

\section{(2) OpenEdition}

1 Journals

\section{Édition électronique}

URL : http://journals.openedition.org/etudesirlandaises/2517

DOI : 10.4000/etudesirlandaises. 2517

ISSN : 2259-8863

\section{Éditeur}

Presses universitaires de Caen

\section{Édition imprimée}

Date de publication : 30 décembre 2011

Pagination : 188-189

ISSN : 0183-973X

\section{Référence électronique}

"At the Hawk's Well and The Cat and the Moon », Études irlandaises [En ligne], 36-2 | 2011, mis en ligne le 30 septembre 201, consulté le 21 septembre 2020. URL : http://journals.openedition.org/ etudesirlandaises/2517; DOI : https://doi.org/10.4000/etudesirlandaises.2517

Ce document a été généré automatiquement le 21 septembre 2020.

\section{(c) (i) (8)}

Études irlandaises est mise à disposition selon les termes de la Licence Creative Commons Attribution - Pas d'Utilisation Commerciale - Partage dans les Mêmes Conditions 4.0 International. 


\section{At the Hawk's Well and The Cat and the Moon}

\section{RÉFÉRENCE}

Andrew Parkin (ed.), At the Hawk's Well and The Cat and the Moon, Manuscript Materials by W. B. Yeats, Ithaca \& London, Cornell UP, 2010, LX15+ 267 p., PR 5904.A95

1 Cet ouvrage répertorie les documents permettant de suivre la création, des esquisses jusqu'aux textes publiés, de At the Hawk's Well et The Cat and the Moon, s'appuyant notamment sur les archives remises par la famille Yeats à la National Library of Ireland. Ces pièces apparemment si différentes ont en commun références autobiographiques et contexte intellectuel et artistique, irlando-japonais. Au folklore irlandais Yeats emprunte le voyage au puits sacré - « The Waters of Immortality » est le premier titre de At the Hawk's Well -, aux mythes gaéliques, Cuchulain, personnage principal dont le nom ne figure pas dans l'oeuvre achevée. Préparé par le théâtre grec, la commedia dell'arte, Craig et Pound, il s'inspire des récits héroïques du nô dans cette première pièce, du comique du kyogen dans la seconde et adopte chants, danses et masques.

2 Suit l'étude du processus de création des deux pièces. L'énergie créatrice de Yeats explique sa précipitation perceptible dans les mots tronqués, corrections, suppressions, hésitations, le pénible «stitching and unstitching " nécessaire « to articulate sweet sounds together", qui accompagne le passage des brouillons manuscrits aux textes dactylographiés, aux épreuves et à la version finale. Cette étude s'enrichit de multiples références aux essais, notes ou programmes. Le brouillon en prose de At the Hawk's Well, commencé probablement en 1916, où l'on découvre toute l'action et deux musiciens, Chorus 1 et Chorus 2, a encore recours aux procédés du théâtre occidental. L'auteur passe rapidement au vers, objet de nombreuses révisions, le dialogue devenant plus direct, plus concis, plus dramatique. Le titre n'est définitif que le brouillon en vers achevé. Lors des répétitions la réécriture se poursuit. Dulac travaille sous le contrôle de Yeats. La pièce, représentée en avril 1916, utilise la convention du nô: un tissu représente le puits, les indications scéniques restent relativement vagues, la référence 
à de petits instruments de musique non identifiés montre que celle-ci n'est pas encore arrêtée. On s'aperçoit alors que trois musiciens sont nécessaires pour le rituel du drap de scène symbolisant l'ouverture et la fermeture des "profondeurs de l'esprit ». La pièce parait dans le Harper's Bazaar en 1917 avec des indications sur l'époque, l'éclairage et les masques - c'est l'avènement d'un nouveau genre dramatique - puis dans To-Day et enfin, révisée, dans The Wild Swans at Coole et Four Plays for Dancers (1921). Après quelques ajustements - via les épreuves, y compris celles préparées pour l'Édition de luxe jamais publiée - le texte définitif voit le jour dans les Collected Plays de 1934. La musique de Dulac figure dans Four Plays for Dancers en 1921. Si les manuscrits de At the Hawk's Well sont abondants, ceux de The Cat and the Moon sont rares. Les premiers brouillons datent sans doute de l'été 1917 ainsi qu'un exemplaire dactylographié qui inclut le chant; tout y est sauf la conclusion définitive. Celle-ci ne figure pas dans le texte publié en 1924 dans The Criterion et The Dial; ébauchée lors de la première production en 1926 - on la trouve sur une feuille du Renvyle House Hotel de 1930 - elle n'est achevée qu'après les représentations de 1931 et incluse dans les épreuves de l'Édition de luxe; ce n'est qu'en 1934 qu'elle est imprimée dans Wheels and Butterfies et les Collected Plays.

3 La transcription a été rendue difficile par l'écriture de Yeats, son orthographe, ses corrections sans cesse modifiées. L'ajout de notes éclaire les reproductions photographiques. Si la musique de Dulac pour At the Hawk's Well est bien connue, celle de The Cat and the Moon ne l'était pas et nous sommes reconnaissants à Parkin de reproduire celle de Lennox Robinson et celle de John Francis Larchet. Voici un apport magistral à la collection des Cornell Yeats. 